RAPID COMMUNICATION

\title{
High-sensitivity C-reactive protein is a good marker of cardiovascular risk in obese children and adolescents
}

\author{
Leandro Soriano-Guillén ${ }^{1,2}$, Bárbara Hernández-García ${ }^{1}$, Jimena Pita $^{2}$, Nieves Domínguez-Garrido ${ }^{1}$, \\ Genoveva Del Río-Camacho ${ }^{1}$ and Adela Rovira ${ }^{2,3}$ \\ ${ }^{1}$ Deparment of Pediatrics, Fundación Jimenez Diaz, University Autonoma of Madrid, Avenida Reyes Catolicos no 2, 28040 Madrid, Spain, ${ }^{2}$ Laboratory of \\ Endocrinology and ${ }^{3}$ Deparment of Endocrinology. Fundacion Jimenez Diaz. University Autonoma of Madrid, Madrid, Spain
}

(Correspondence should be addressed to L Soriano-Guillén; Email: lsoriano@fjd.es; leansor4@hotmail.com)

\begin{abstract}
Objective: We intend to assess the utility of the high-sensitivity C-reactive protein (hs-CRP) as a marker of cardiovascular risk in obese children and adolescents.

Methods: The study included children and adolescents between 6 and 18 years of age with a body mass index (BMI) higher than 2 SDS. All the patients had their blood pressure taken and hs-CRP, hepatic function, lipid profile and uric acid were determined after $12 \mathrm{~h}$ of fasting. Likewise, an oral glucose tolerance test was performed, determining basal glucose and insulin levels, and after stimulus. We considered the presence of metabolic syndrome when the obese children and teenagers showed at least two of the following conditions: decreased high density lipoprotein (HDL)-cholesterol, hypertriglyceridemia, hypertension or alteration in glucose metabolism.

Results: Out of the 115 obese children studied, 24\% showed signs of metabolic syndrome. Those with metabolic syndrome presented higher levels of hs-CRP (mean: $3.8 \mathrm{mg} / \mathrm{l}$; 95\% CI: 2.8-4.8) in comparison with the obese patients who did not show signs of metabolic syndrome (mean: $2 \mathrm{mg} / \mathrm{l}$; 95\% CI: 1.5-2.5). After a multivariate analysis, the variables that appear to influence the changes in hs-CRP were BMI, triglycerides and HDL-cholesterol levels.

Conclusion: The hs-CRP is a useful tool for early diagnosis of cardiovascular risk in obese children and teenagers.
\end{abstract}

European Journal of Endocrinology 159 R1-R4

\section{Introduction}

The rise in C-reactive protein (CRP) as a response to the increase in the secretion of cytokines of adipose origin detected in obese individuals (1) has been used as a marker of cardiovascular risk and diabetes in adults $(2,3)$. When measured with new high-sensitivity assays, the levels of CRP have proven to predict future cardiovascular risk. Among apparently healthy men and women, the levels of high-sensitivity-CRP (hs-CRP) of $<1,1-3$ and $>3 \mathrm{mg} / \mathrm{l}$ distinguish between those at low, moderate and high risk of future cardiovascular disease (4).

Later studies have shown high values of hs-CRP among obese children and adolescents, indicating that in early stages there already exists a certain level of inflammation in relation to the non-obese population (5-8). However, not many data are available that guarantee its utility as a marker of cardiovascular risk and diabetes in childhood $(7,8)$. Therefore, our intention is to study the levels of hs-CRP in obese children and adolescents with and without metabolic syndrome to evaluate the utility of this parameter as a method of early diagnosis of cardiovascular risk in early stages of life and to analyse whether there are variables associated with higher levels of CRP.

\section{Subjects and methods}

This is a cross-sectional study of obese children and adolescents. From all children and adolescents between 6 and 18 years of age, who came to our Unit (Pediatric Endocrinology Unit of Hospital Fundacion Jimenez Díaz, Madrid) and who were suspiciously obese, we recruited those who had body mass index $(\mathrm{BMI})>2$ SDS for their age and sex according to Spanish BMI data and who did not suffer any chronic illness or acute infectious disease.

Considering that the average level of hs-CRP in the normal population is around $1 \mathrm{mg} / \mathrm{l}$, to achieve a $50 \%$ difference in hs-CRP levels among obese individuals with and without metabolic syndrome, it is necessary to obtain a minimum sample size of 90 patients with a statistical power of $90 \%$ and a confidence level of $95 \%$.

These children and adolescents had their weight $(\mathrm{kg})$, height $(\mathrm{cm})$ and blood pressure $(\mathrm{mmHg})$ taken thrice during a period of time of $10 \mathrm{~min}$ (we calculated the mean 
systolic and diastolic blood pressure). After $12 \mathrm{~h}$ of night fasting, blood samples were taken to measure hs-CRP, lipid profile, hepatic function, basal glucose and insulin levels. Later, a glucose tolerance test was carried out $(1.7 \mathrm{~g} \times \mathrm{kg}$, maximum $=75 \mathrm{~g})$ and then, $120 \mathrm{~min}$ later, glucose and insulin levels were measured again. Taking into account that all our patients met one criterion of metabolic syndrome (being obese), metabolic syndrome was considered when at least two other of the following criteria were present $(9,10)$ : HDL cholesterol below 5 percentile and/or triglycerides above 95 percentile for the age and sex, diastolic and/or systolic blood pressure higher than 95 percentile for the age, sex and height (11), and alteration in glucose metabolism according to criteria of the American Society of Diabetes (12). Other study variables taken into account include age, sex, race and Tanner stages of pubertal development.

This project was approved by the Ethics Committee of our hospital and it was compulsory to sign the corresponding informed consent in order to take part.

Student's $t$-test was used to compare independent data of normal distribution, applying the MannWhitney $U$ test when the variables did not follow a normal distribution. Finally, in order to analyse the correlation between the levels of hs-CRP and the study variables, a univariate analysis was carried out and later a multivariate linear regression was performed. The data were analysed using the SAS software package (SAS Institute Inc., Cary, NC, USA).

\section{Results}

The data have been expressed as mean and in 95\% confidence interval. A total of 115 obese children and adolescents were studied, of whom 28 met metabolic syndrome criteria $(24 \%)$. The children and adolescents with metabolic syndrome presented significantly higher levels of hs-CRP (mean: $3.8 \mathrm{mg} / \mathrm{l}$; 95\% CI: 2.8-4.8) in comparison with those who did not present metabolic syndrome (mean: $2 \mathrm{mg} / \mathrm{l}$; 95\% CI: 1.5-2.5) (Table 1). There were also significant differences between these two groups when analysing the levels of basal insulin and 120 min later, triglycerides, HDL-cholesterol and uric acid. By contrast, no significant differences between the two groups were observed regarding age and BMI. Finally, there were no differences in the levels of hs-CRP when comparing the different pubertal stages, race and sex.

After performing a simple linear regression between the different quantitative variables that could affect the hs-CRP, the only ones that showed a linear relationship were BMI $(r=0.35, P<0.01)$, basal insulin $(r=0.3$, $P=0.01)$, triglycerides $(r=0.33, P<0.01)$ and HDLcholesterol $(r=-0.3, P<0.01)$ (Fig. 1), although with a remarkable dispersion. Later on, a multivariate linear regression model was built considering hs-CRP as a dependent variable and BMI, basal insulin, triglycerides and HDL-cholesterol as independent variables. In this model, the only significant variables were BMI, triglycerides and HDL-cholesterol, with a determination coefficient of $R^{2}=0.25$.

\section{Conclusion}

The hs-CRP is significantly increased in obese children and adolescents with metabolic syndrome in comparison with the group without metabolic syndrome. With this study, we have shown that BMI is not the only variable that can affect the increase in hs-CRP, unlike what has been described in previous studies $(5,6)$. Therefore, a possible interaction is found between hs-CRP and the levels of triglycerides and HDL-cholesterol, suggesting its utility as a metabolic risk marker $(7,8)$. This interaction between hs-CRP, triglycerides and HDL-cholesterol could be mediated by different cytokines of adipose origin that

Table 1 Comparison of clinical and biochemical data among obese children with or without metabolic syndrome.

\begin{tabular}{|c|c|c|c|}
\hline & Metabolic syndrome $(n=28)$ & $\begin{array}{l}\text { Without metabolic syndrome } \\
\qquad(n=87)\end{array}$ & $P$ \\
\hline Hs-CRP (mg/l) & $3.8(2.8-4.8)$ & $2(1.5-2.5)$ & $<0.01^{a}$ \\
\hline Age (years) & $11.4(10.4-12.4)$ & $10.6(9.7-11.3)$ & $0.25^{\mathrm{b}}$ \\
\hline BMI (SDS) & $4.7(4-5.4)$ & $4(3.6-4.4)$ & $0.06^{\mathrm{b}}$ \\
\hline ALAT (UI/I) & $30(21-39)$ & $28(23-33)$ & $0.61^{\mathrm{a}}$ \\
\hline ASAT (UI/I) & $42(22-62)$ & $27(19-36)$ & $0.13^{\mathrm{a}}$ \\
\hline Glucose (mmol/l) & $4.47(4.30-4.64)$ & $4.42(4.29-4.55)$ & $0.64^{\mathrm{b}}$ \\
\hline Basal insulin $(\mu \mathrm{Ul} / \mathrm{ml})$ & $32.1(25.2-38.9)$ & $16.3(14.2-18.4)$ & $<0.001^{a}$ \\
\hline HOMA-index & $6.37(4.90-7.84)$ & $3.22(2.75-3.69)$ & $<0.001^{a}$ \\
\hline Glucose $120^{\prime}(\mathrm{mmol} / \mathrm{l})$ & $6.88(6.30-7.46)$ & $6.28(5.92-6.61)$ & $0.08^{\mathrm{b}}$ \\
\hline Insulin $120^{\prime}(\mu \mathrm{Ul} / \mathrm{ml})$ & $182(129-235)$ & $77(63-91)$ & $<0.001^{a}$ \\
\hline Total cholesterol $(\mathrm{mmol} / \mathrm{l})$ & $4.41(3.83-4.99)$ & $4.14(3.81-4.31)$ & $0.16^{\mathrm{b}}$ \\
\hline Triglycerides $(\mathrm{mmol} / \mathrm{l})$ & $1.72(1.57-1.87)$ & $0.80(0.73-0.87)$ & $<0.001^{b}$ \\
\hline HDL-cholesterol (mmol/l) & $0.96(0.93-0.99)$ & $1.30(1.27-1.33)$ & $<0.001^{b}$ \\
\hline LDL-cholesterol $(\mathrm{mmol} / \mathrm{l})$ & $2.71(2.42-3.02)$ & $2.48(2.31-2.65)$ & $0.16^{\mathrm{b}}$ \\
\hline Uric acid $(\mu \mathrm{mol} / \mathrm{l})$ & $351(314-388)$ & $283(267-299)$ & $<0.01^{\mathrm{b}}$ \\
\hline
\end{tabular}

ALAT, alanine aminotransferase; ASAT, aspartate aminotransferase.

aMann-Whitney $U$ test for independent non-parametric data.

${ }^{\mathrm{b}}$ Student's $t$-test for independent parametric data. 

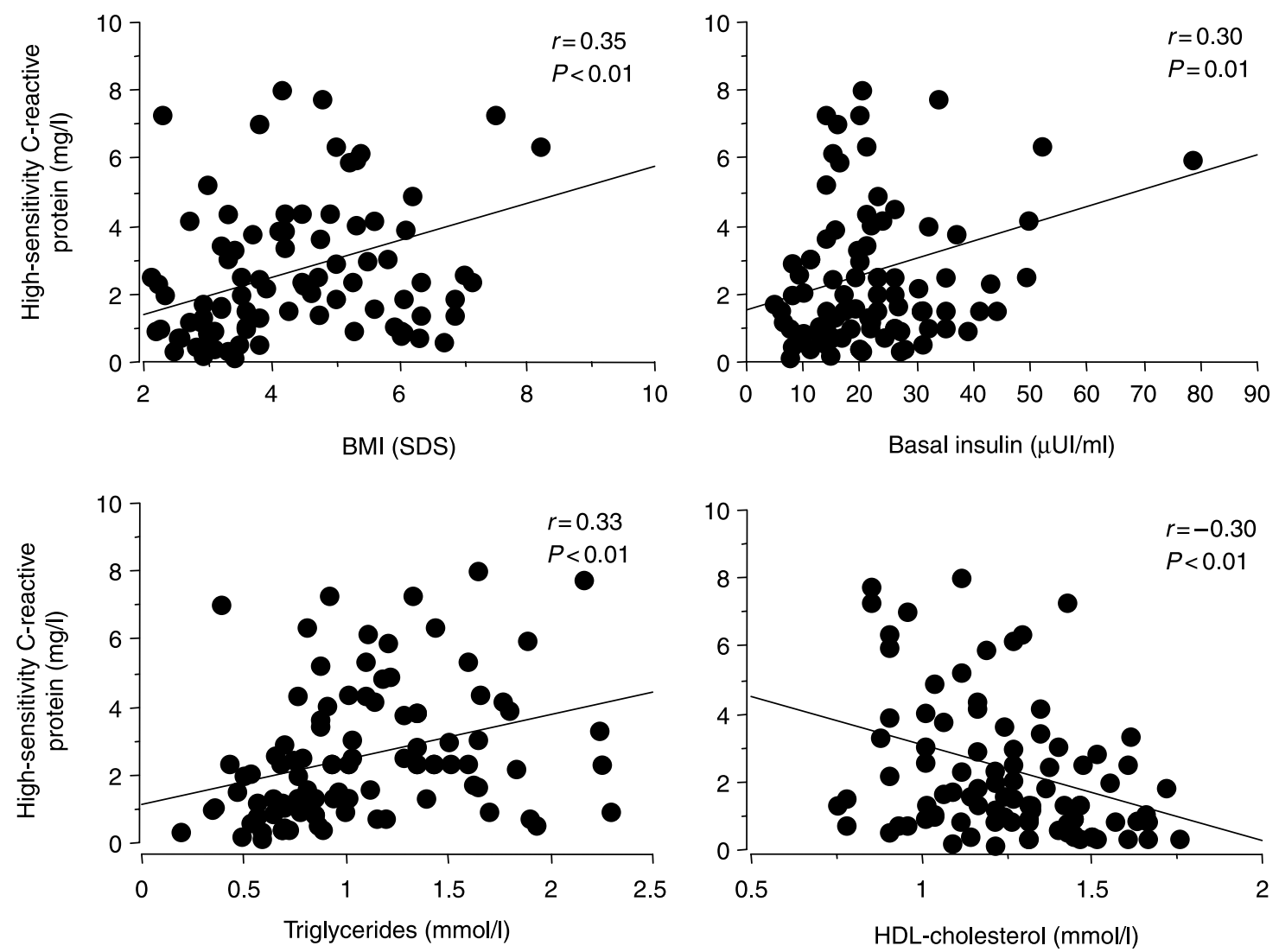

Figure 1 Linear regression analysis among hs-CRP and BMI, triglycerides, HDL-cholesterol and basal insulin.

in some genetically predisposed individuals are elevated in relation to higher abdominal adiposity (1). However, more prospective studies will be necessary in order to clarify this relationship.

The absence of influence of age or Tanner pubertal stage in hs-CRP levels shows the utility of this parameter as a metabolic risk marker in early stages of life (8).

A limitation of our study is that with the multivariate model built we only partially explain the changes observed in hs-CRP. Therefore, it is necessary to carry out more studies that take into consideration other variables such as adiponectin, interleukin- 6 and tumor necrosis factor- $\alpha$, considered by other authors and which in this case have not been studied (13).

In short, hs-CRP seems to be an excellent marker in order to distinguish the presence of metabolic syndrome among obese children and adolescents and could be a useful tool for the early detection of cardiovascular risk factors among this population.

\section{Disclosure}

The work presented does not have any source of funding. There is no conflict of interest that would prejudice its impartiality.

\section{References}

1 Trujillo ME \& Scherer P. Adipose tissue-derived factors: impact on health disease. Endocrine Reviews 200627 762-778.

2 Mendall MA, Patel P, Ballam L, Strachan D \& Northfield TC. C reactive protein and its relation to cardiovascular risk factors: a population based cross sectional study. BMJ 1996312 10611065.

3 Han TS, Sattar N, Williams K, González-Villalpando C, Lean ME \& Haffner SM. Prospective study of c-reactive protein in relation to the development of diabetes and metabolic syndrome in the Mexico City Diabetes Study. Diabetes Care 200225 2016-2021.

4 Yeh ET. High-sensitivity c-reactive protein as a risk assessment tool for cardiovascular disease. Clinical Cardiology 200528 408-412.

5 Wu DM, Chu NF, Shen MH \& Wang SC. Obesity, plasma high sensitivity c-reactive protein levels and insulin resistance status among school children in Taiwan. Clinical Biochemistry 200639 $810-815$.

6 Retnakaran R, Hanley AJG, Connelly PW, Harris SB \& Zinman B. Elevated C-reactive protein in Native Canadian children: an ominous early complication of childhood obesity. Diabetes, Obesity and Metabolism $2006 \mathbf{8}$ 483-491.

7 Guran O, Akalin F, Ayabakan C, Dereli FY \& Haklar G. Highsensitivity c-reactive protein in children at risk for coronary artery disease. Acta Paediatrica 200796 1214-1229.

8 Oliveira AC, Oliveira AM, Almeida MS, Silva AM, Adan L \& Ladeia AM. Alanine aminotransferase and high sensitivity c-reactive protein: correlates of cardiovascular risk factors in youth. Journal of Pediatrics 2008152 337-342.

9 Cook S, Weitzman M, Aungier P, Nguyen M \& Dietz WH. Prevalence of a metabolic syndrome phenotype in adolescents: 
findings from the third National Health and Nutrition Examination Survey, 1988-1994. Archives of Pediatrics and Adolescent Medicine $2003157821-827$.

10 Lopez-Capape M, Alonso M, Colino E, Mustieles C, Corbaton J \& Barrio R. Frequency of the metabolic syndrome in obese Spanish pediatric population. European Journal of Endocrinology 2006155 313-319.

11 National high blood pressure education program working group on high blood pressure in children and adolescents. The Fourth report on diagnosis, evaluation, and treatment of high blood pressure in children and adolescents. Pediatrics 2004114 $555-576$.
12 American Diabetes Association. Diagnosis and classification of diabetes mellitus. Diabetes Care 200831 S55-S60.

13 Winer JC, Zern TL, Taksali SE, Dziura J, Cali AMG, Wollschlager M, Seyal AA, Weiss R, Burgert TS \& Caprio S. Adiponectin in childhood and adolescent obesity and its association with inflammatory markers and components of the metabolic syndrome. Journal of Clinical Endocrinology and Metabolism 200691 4415-4423.

Received 17 April 2008

Accepted 22 April 2008 